\title{
The role of chemokines in Schistosoma mansoni infection: insights from human disease and murine models
}

\author{
Adriano LS Souza, Silvio R Sousa-Pereira*, Mauro M Teixeira, José R Lambertucci*, \\ Antonio L Teixeira*/+
}

\begin{abstract}
Laboratório de Imunofarmacologia, Departamento de Bioquímica e Imunologia, Instituto de Ciências Biológicas *Divisão de Infectologia e Medicina Tropical, Departamento de Clínica Médica, Faculdade de Medicina, Universidade Federal de Minas Gerais, Av. Alfredo Balena 190, 30130-100 Belo Horizonte, MG, Brasil
\end{abstract}

Chemokines are a superfamily of low-molecular-weight cytokines that were initially described for their chemoattractant activity. It is now clear chemokines have several other activities that modulate immune processes. More than 50 chemokines ligands and at least 19 receptors have been described to date. Depending on the number of $N$-terminal cysteine residues, chemokines are grouped in the subfamilies CXC, CC, C or CX3C. A growing body of evidence suggests a role for chemokines in the pathogenesis of several inflammatory diseases. Our studies involving mice and humans infected with Schistosoma mansoni suggest an important role of the chemokine CCL3 and its receptors (CCR1 and CCR5) in the pathogenesis of severe schistosomiasis. We suggest that the differential activation of CCR1 or CCR5 during the course of schistosomiasis may dictate the outcome of the disease.

Key words: schistosomiasis - chemokines - inflammation

While many good reviews have been published on the pathogenesis of schistosomiasis and the role of cytokines on tissue and vascular events leading to the main alterations associated with disease morbidity and mortality (Vennervald \& Dunne 2004), the specific contribution of chemokines to these changes has not been addressed in details. Accumulating data in the recent literature justifies the need for an integrated re-examination of this issue with a focus on this important group of inflammatory mediators. Thus, this review aims at confronting complementary evidence from human and mice studies to sum up that chemokines are indeed relevant co-players in the intricate mechanisms that explain why some schistosomiasis patients deal relatively well with the infection while others are prone to develop severe forms of the disease.

\section{Chemokines: structure and function}

Chemokines belong to the superfamily of low-molecular-weight cytokines that were initially described for their chemotactic activity. They are important mediators of cell migration. However, it is clear that chemokines affect several other processes, including differentiation and activation, tissue specific homing of leukocytes under physiologic conditions, infiltration of cells in sites of tissue injury. By performing the activities described above, chemokines have been shown to play a relevant role in angiogenesis, infectious, and autoimmune diseases

Financial support: UNICEF/UNDP/World Bank/WHO Special Programme for Research and Training in Tropical Diseases (TDR A20748)/CNPq/Fapemig

${ }^{+}$Corresponding author: altexr@gmail.com

Received 25 May 2006

Accepted 26 June 2006
(Mackay 2001). More than 50 chemokine ligands and at least 19 signalizing chemokine receptors are known today in both humans and mice (Charo \& Ransohoff 2006).

Despite the low sequence similarity between some chemokines, an important feature of this class of molecules is their disulfide-stabilized tertiary structure composed of three beta sheets linked by short loops with a carboxyterminal alpha helix in a Greek key formation. Depending on the number of N-terminal cysteine residues they are grouped in the subfamilies CXC (two N-terminal cysteines separated by one amino-acid residue), CC (two directly linked cysteines), $\mathrm{C}$ (only one $\mathrm{N}$-teminal cysteine) or CX3C (two N-terminal cysteines separated by three aminoacid residues) (Olson \& Ley 2002). This classification is helpful since there seems to be some specificity regarding the cellular types responding to a certain group of chemokines. Nonetheless, chemokines commonly bind to several receptors, and cells, in turn, may bear multiple types of chemokine receptors, which may result in considerable superposition or redundancy of responses.

Differently from other cytokines that act on tyrosine kinase receptors, all chemokines signal via G proteincoupled seven transmembrane spanning receptors (Proudfoot et al. 2003). The nomenclature of chemokine receptors is directly based on the type of chemokine that binds them. Six years have passed since the IUPHAR deliberation on the systematic nomenclature of chemokine ligands and receptors (Murphy et al. 2000). Although the system was initially developed for human chemokines, it may be extended to rodents as well. Thus, this nomenclature will be employed in this review.

\section{Chemokines in schistosomiasis}

Abundant literature attests the role of chemokines in the physiopathology of several diseases including atopic dermatitis, leishmaniosis, rheumatoid arthritis, multiple sclerosis, asthma, pulmonary sarcoidosis, sepsis, atherosclerosis, HIV infection, ulcerative colitis among others 
(reviewed in Gerard \& Rollings 2001, Maurer \& von Stebut 2004, Charo \& Ransohoff 2006). These studies are based on strategies such as the use of neutralizing antibodies, knockout mice, peptidic and non-peptidic antagonists. Besides, the identification and/or measurement of chemokines in human biological fluids, i.e. serum, plasma or cerebrospinal fluid (CSF), may suggest their involvement in the pathological process.

Some studies have focused on the role of chemokines in schistosomiasis. Data obtained from murine models suggest that chemokines dictate the type and intensity of inflammatory infiltrate during the granulomatous response against egg antigens (Qiu et al. 2001). For instance, the chemokine macrophage inflammatory protein-1a (MIP-1a/ CCL3) was released after embolization of schistosome eggs into the lungs of immunized mice. Interestingly the antibody neutralization of CCL3 decreased the size of the granuloma (Lukacs et al. 1994a,b). In addition, CCR1-deficient mice exhibited a $40 \%$ reduction in egg-induced pulmonary granulomas corroborates this assumption (Gao et al. 1997). It is important to note that data from CCR1-deficient mice must not be considered equivalent to the results involving CCL3 knockouts as CCL3 may bind to other receptors, including CCR5 (Post et al. 1995, Nibbs et al. 1997). The studies described only evaluated the inflammatory response after injection of eggs into animals. In our experiments in Schistosoma mansoni-infected mice, we found that CCL3-deficient mice displayed decreased liver eosinophilic peroxidase activity (EPO) and hydroxyproline content (Souza et al. 2005). These findings paralleled reduced worm burden and egg content in this organ. The mechanisms responsible for the reduced parasitic burden are still unclear. However, we found a significant reduction in granuloma area compared to wild type animals and this effect was clearly dependent on the role of the chemokine on pathology (Souza et al. 2005). These results indicate that the granulomatous response and schistosomiasis is less severe in the absence of CCL3.

Similar results were also shown for other knockout mice. When CCR2-deficient mice were subjected to the model of venous injection and subsequent lung embolization with schistosome egg antigen (SEA)-coupled beads, a decrease in granuloma size, attributed to the reduction of the number of lymphocytes, was observed (Warmington et al. 1999). The mRNA levels for interleukin(IL)-4 and interferon(IFN)- $\gamma$ were found to be decreased, while there were increased mRNA levels for CCR2 ligands such as CCL2, CCL7, and CCL12. This result may suggest that the synthesis of CCR2 ligands would be regulated by a receptor activation-induced negative feedback mechanism (Warmington et al. 1999). The effect of CCR2 depletion on the course of $S$. mansoni infection has not been reported to date.

Intravenous injection of schistosoma eggs into CCR8deficient mice resulted in impaired Th-2 cytokines synthesis and significantly reduced eosinophilic infiltration in lung granulomas (Chensue et al. 2001). The reduction in Th-2 cytokine synthesis in CCR8-deficient mice corroborates the fact that this chemokine receptor mediates selective expression of Th-2 lymphocytes. It is worth mentioning that, with the exception of our study, the data discussed previously were based on a model of intravenous injection of either eggs or antigen-coupled beads, which causes pulmonary embolization followed by granuloma formation. Although this model has the advantage of synchronizing the kinetics of granuloma development, it does not take into account the host-parasite cross-talking that may have profound influence on the regulation of inflammatory response. Moreover the lung is not the most affected organ by naturally occurring granulomatous response in schistosomiasis.

The CCL3 chemokine seemed to be particularly relevant in schistosomiasis. This assumption was reinforced by studies involving human subjects. We found that, when compared with uninfected individuals, infected patients had elevated plasma concentrations of CCL3, CCL5, and CCL11 (Falcão et al. 2002). When patients were grouped according to disease severity (intestinal $\mathrm{x}$ hepatosplenic), subjects with increased plasma concentration of CCL3 $(>400 \mathrm{pM})$ had a 10 times greater risk of displaying hepatosplenic form of the disease (Falcão et al. 2002). This preliminary data was confirmed in a second subset of chronically infected patients who had been classified by ultrasonography (Souza et al. 2005). It was also demonstrated that peripheral blood mononuclear cells (PBMC) from infected patients, when exposed in vitro to SEA-coupled beads, produced high levels of CCL3 and that this production was antigen-specific (Falcão et al. 2002). Treatment of PBMC from hepatosplenic patients with met-RANTES, a CCR1, and CCR5 antagonist, was capable of inhibiting the cellular reactivity in this in vitro granuloma model. However the treatment of PBMC from intestinal patients determined an exacerbation of the cellular response. These apparently conflicting results remained an issue of difficult interpretation and prompt us to suggest that the balance between the expression of these two chemokine receptors, CCR1 and CCR5, are crucial to the outcome of schistosomiasis infection (see below). It has also been shown that exacerbation of the in vitro granulomatous response induced by nitro L-arginine methyl ester (L-NAME), a nitric oxidase inhibitor, treatment is associated with increases in CCL3 in the culture supernatant of human PBMC (Oliveira et al. 1999).

Recently, we also investigated the chemokine levels in serum and CSF of schistosomal myeloradiculopathy (SMR) patients (Sousa-Pereira et al. 2006). SMR is the most common neurological form of $S$. mansoni infection and seems to be determined by the inflammatory response to schistosomal eggs ectopically deposited in the nervous system (Nobre et al. 2001, Silva et al. 2004). SMR patients presented increased serum levels of CCL11 and CCL24 when compared to controls. In contrast to the determinations in serum, there were no differences in the concentration of chemokines in CSF of SMR patients when compared to neurologically healthy controls. This unexpected finding may be consistent with a lack of intrathecal production of the chemokines (Sousa-Pereira et al. 2006).

The CCL 3 receptors, CCR 1 and CCR5, are expressed in a series of cell types, including neutrophils, monocytes, macrophages, T and B lymphocytes, eosinophils, dendritic cells (DC), natural killer (NK) cells, thymocytes, plate- 
lets, endothelial, and striated cardiac muscle cells (reviewed in Menten et al. 2002). At least in the context of schistosoma granuloma, macrophages are the main source of this chemokine (Lukacs et al. 1993). It is believed that, when activated by CCL3, macrophages may release additional quantities of this same chemokine, causing extra influx of macrophages. Considering the major type of T helper lymphocyte capable of synthetizing it, CCL3 would be considered a Th1 chemokine (Schrum et al. 1996, Ritz et al. 2004). CCL3 was also shown to induce selective migration of Th1 lymphocytes (Siveke \& Hamann 1998). However, as the major source of CCL3 in the schistosome granuloma is the macrophage, there is the "odd situation" of Th2 polarization in egg-induced pulmonary granuloma associated with the expression of CCL3.

The next step to understand the role of chemokines in schistosomiasis pathogenesis would be the investigation of the course of the infection in knockout mice for other chemokine receptors for CCL3 and CCL5, i.e. CCR1 and CCR5. Data from CCR1-deficient mice indicated that this receptor was at least partially responsible for the detrimental effects of CCL3 (Gao et al. 1997). The role of CCR5 in models of inflammation is rather controversial. Either inhibition or exacerbation of general aspects of inflammation has been observed. CCR5-deficient mice display reduced arthritis incidence and also inhibited anti-collagen antibody production (Bao et al. 2005). These results are in line with the inhibition of arthritis in rhesus monkeys treated with a CCR5 antagonist (Vierboom et al. 2005). CCR5-deficient mice infected with Trypanosoma cruzi also exhibited less myocarditis (Machado et al. 2005). On the other hand, CCR5 deletion is associated with an increase in delayed-type hypersensitivity (DTH) and enhancement of T-dependent humoral response (Zhou et al. 1998), as well as an improved tumor growth control and a more intense graft rejection (Welniak et al. 2004).

These contradictory results prompted us to investigate the course of schistosomiasis infection in CCR5-/mice. We noticed that of CCR5-/- mice developed a more severe infection than wild type mice. This was not only confirmed by the exacerbation of a series of inflammatory parameters, such as liver $\mathrm{N}$-acetylglucosaminidase (NAG) activity, hydroxyproline concentration, and increased granuloma area, but also by the enhancement (beyond two-fold) in mortality rates. At a first look, these results may sound conflicting considering the opposite effects of CCL3 deletion on schistosomiasis (Souza 2005).

Interestingly, as opposed to the current view from many research groups that the granuloma-associated pathology in mice is Th2-mediated, it was demonstrated that an inflammatory response amplified by complete Freund adjuvant (CFA) immunization, a treatment that is typically considered to induce Th1 polarization, exacerbates the pathology in C57BL6 S. mansoni infected mice (Rutitizky et al. 2001, Stadecker et al. 2004). More recently, the same group has shown that a new class of $\mathrm{T}$ helper lymphocytes, named T CD4 ${ }^{+}$IL-17, were crucial for the development of these exacerbated lesions (Rutitizky et al. 2005), and importantly, that these lymphocytes were characterized by the synthesis of the cytokines tumor necrosis factor (TNF)- $\alpha$ and IL- 6 and chemokines CCL2, CCL3, and
CXCL8 (Prof. Miguel Stadecker, pers. commun.). It is worth emphasizing that the same chemokines were shown to be elevated in the plasma of patients suffering the hepatosplenic form of schistosomiasis (Falcão et al. 2002).

\section{A model for the balance of expression of two chemokine receptors and the outcome of $S$. mansoni infection}

The main question in schistosomiasis research relates to the explanation of why the great percentage of $S$. mansoni infected hosts display only mild symptoms, while a minority suffers from severe, sometimes life threatening, hepatosplenic symptoms (Fallon 2000). Conflicting data from different species infected with S. mansoni should also be reconciled in a comprehensive model of disease pathogenesis. Based on what has been discussed above, we propose a model in which the balance between two chemokine receptors, namely CCR 1 and CCR 5 , may exert a crucial role on the final presentation of $S$. mansoni infection. We do not suggest, however, that the roles of other mediators are to be disregarded, but that the two chemokine receptors are important players in this multifaceted inflammatory context.

It is known that other chemokines exhibit significant affinity for the receptors used by CCL3. For instance, CCL5, CCL14, CCL15, and CCL23 are CCR1 agonists while CCL4, CCL5, and CCL8 are CCR5 agonists (Murphy et al. 2000). Thus, a given chemokine can act on different chemokine receptors, while one specific receptor may be the target of several chemokines what would suggest that this system operates with considerable redundancy. However, this view is not accepted by all researchers, since some suggest that some level of compartimentalization exists in the chemokine system. This scenario is depicted, for instance, in some reviews that deal with the rational design of new drugs based on the action of chemokines (Proudfoot et al. 2000, 2003, Proudfoot 2002, Johnson et al. 2004).

We suggest that the influence of the balance between the CCR 1 and CCR 5 chemokine receptors on the clinical presentation of schistosomiasis depends on the occurrence of a fine temporal and spatial tuning of the action of chemokines to reach specificity of response.

The Figure is a graphic representation of this hypothesis. We propose that the majority of infected hosts or patients, who present mild form of disease, are able to develop an adaptive immune response in which there is preponderance of CCR5 receptor activation over CCR1. On the other hand, severe forms of disease would result from unbalanced chemokine receptor activation towards an increased activation of CCR1 over CCR5. CCR1 activation would be predominantly mediated by CCL3, while CCR 5 activation by CCL5. The reason for the need of fine mechanisms regulating spatial-temporal specificity of CCL3 and CCL5 resides in complementary experimental observations from various research groups indicating that these chemokines exhibit apparently opposing activities regarding the clinical presentation of disease, despite sharing nearly identical receptor affinity.

Evidence that supports the idea that CCL3 has a harmful role in schistosomiasis derives from the following experimental observations: (1) a correlation between high 


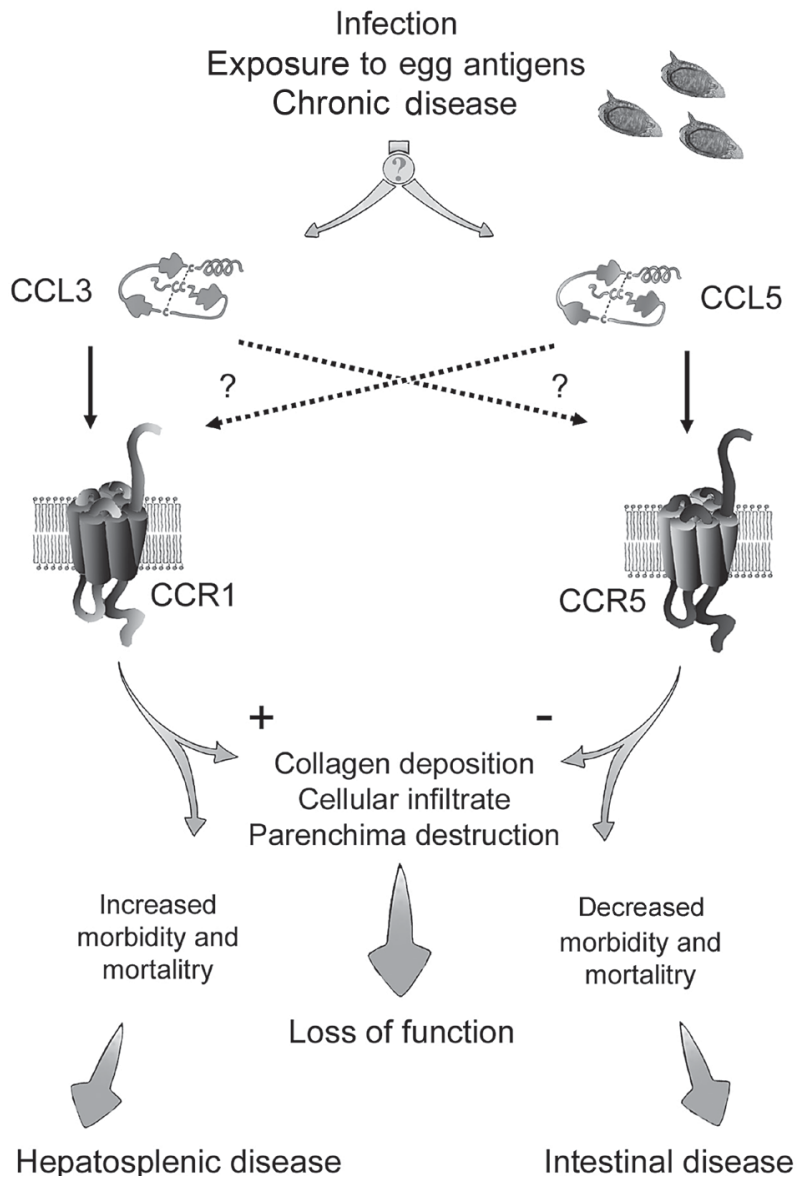

Hypothesis for the balance of action of chemokines on CCR1 and CCR5 and influence over clinical presentation of schistosomiasis. See comments in the text.

levels of CCL3 and the presentation of hepatosplenic disease in schistosomiasis patients (Falcão et al. 2002, Souza et al. 2005, Sousa-Pereira et al. 2006); (2) the development of milder disease in a model of CCL3-deficent S. mansoni infected mice (Souza et al. 2005); (3) a 40\% inhibition in lung granulomas in CCR1 knockout mice subjected to intravenous injection of S. mansoni eggs (Gao et al. 1997); and (4) the phenotypic description of a class of IL-17producing T helper lymphocyte (Rutitzky et al. 2005), that is also characterized by producing the chemokines CCL2, CCL3, and CXCL8, with a demonstrated role in the development of severe lesions associated with increased morbidity and mortality in schistosomiasis (Prof. Stadecker, pers. commun.).

Other set of evidences suggests that another chemokine, most likely CCL5, plays a modulatory role in the immunopathology of schistosomiasis preventing the emergence of severe forms of the disease: (1) a more severe schistosomiasis infection in CCR5-deficient mice (Souza 2005); (2) a correlation between the risk of presentation of periportal fibrosis and elevated TNF- $\alpha$ associated with low CCL5 concentrations in the supernatant of PBMC from schistosomiasis patients stimulated with SEA (Booth et al. 2004); (3) an increase in 50\% on the size of pulmonary granulomas from mice subjected to intravenous injection of SEA-coupled beads and treated with antibody against CCL5 (Chensue et al. 1999); (4) the observation of increased CCR5 expression on lymphocytes from intestinal patients and low expression of the same receptor in both control and hepatosplenic individuals (Prof. Andréa Teixeira, pers. commun.); and (5) the tendency towards exacerbation of cellular reactivity of PBMC from intestinal patients treated with met-RANTES in the in vitro granuloma model, contrary to the intense inhibition observed with cells from hepatosplenic patients (Falcão et al. 2002). In hepatosplenic patients, the modulatory CCR5 wing would be absent. Thus, in these patients, the CCR1 and CCR 5 combined antagonism of met-RANTES equals the isolate inhibition of CCR1 activation, causing granuloma reduction. In intestinal patients, whose CCR5 expression supersedes that of CCR1, met-RANTES activity turns to be harmful.

In summary, accumulating evidence in the literature suggests that chemokines are more than epiphenomena of adaptive immune responses. This important group of mediators may be related to the outcome of infectious diseases at least in the context of S. mansoni infection. Moreover the presence of key chemokines in plasma or serum, besides reflecting pathogenic mechanisms, may be used as surrogated markers of disease severity. This support the efforts which are being made to design new drugs that could act on the chemokine system and we are hopeful that these drugs may be used for the management of several inflammatory conditions.

\section{REFERENCES}

Bao L, Zhu Y, Zhu J, Lindgren JU 2005. Decreased IgG production but increased MIP-1beta expression in collagen-induced arthritis in $\mathrm{C}-\mathrm{C}$ chemokine receptor 5-deficient mice. Cytokine 31: 64-71.

Booth M, Mwatha JK, Joseph S, Jones FM, Kadzo H, Ireri E, Kazibwe F, Kemijumbi J, Kariuki C, Kimani G, Ouma JH, Kabatereine NB, Vennervald BJ, Dunne DW 2004. Periportal fibrosis in human Schistosoma mansoni infection is associated with low IL-10, low IFN-gamma, high TNFalpha, or low RANTES, depending on age and gender. $J$ Immunol 172: 1295-303.

Charo IF, Ransohoff RM 2006. The many roles of chemokines and chemokine receptors in inflammation. $N$ Engl $J$ Med 354: 610-621.

Chensue SW, Warmington KS, Allenspach EJ, Lu B, Gerard C, Kunkel SL, Lukacs NW 1999. Differential expression and cross-regulatory function of RANTES during mycobacterial (type 1) and schistosomal (type 2) antigen-elicited granulomatous inflammation. J Immunol 163: 165-73.

Chensue, SW, Lukacs NW, Yang TY, Shang X, Frait KA, Kunkel SL, Kung T, Wiekowski MT, Hedrick JA, Cook DN, Zingoni A, Narula SK, Zlotnik A, Barrat FJ, O'Garra A, Napolitano M, Lira SA 2001. Aberrant in vivo T helper type 2 cell response and impaired eosinophil recruitment in $\mathrm{CC}$ chemokine receptor 8 knockout mice. J Exp Med 193: 573584.

Falcão PL, Correa-Oliveira R, Fraga LAO, Talvani A, Proudfoot AE, Wells TNC, Williams TJ, Jose PJ, Teixeira MM 2002. 
Plasma concentrations and role of macrophage inflammatory protein-1a (MIP-1a/CCL3) during chronic Schistosoma mansoni infection in humans. J Infect Dis 186: 1696-1700.

Fallon PG 2000. Immunopathology of schistosomiasis: a cautionary tale of mice and men. Immunol Today 21: 29-35.

Gao JL, Wynn, TA, Chang Y, Lee EJ, Broxmeyer HE, Cooper S, Tiffany HL, Wespahl H, Kwon-Chung J, Murphy PM 1997. Impaired host defense, hematopoiesis, granulomatous inflammation, and type 1-type2, cytokine balance in mice lacking CC chemokine receptor 1. J Exp Med 185: 1959-1968.

Gerard C, Rollins BJ 2001. Chemokines and disease. Nat Immunol 2: 108-115.

Johnson Z, Power CA, Weiss C, Rintelen F, Ji H, Ruckle T, Camps M, Wells TN, Schwarz MK, Proudfoot AE, Rommel C 2004. Chemokine inhibition-why, when, where, which and how? Biochem Soc Trans 32: 366-377.

Lukacs NW, Chensue SW, Smith RE, Strieter RM, Warmington K, Wilke C, Kunkel SL 1994a. Production of monocyte chemoattractant protein-1 and macrophage inflammatory protein-1 alpha by inflammatory granuloma fibroblasts. $\mathrm{Am}$ J Pathol 144: 711-718.

Lukacs NW, Kunkel SL, Strieter RM, Warmington K, Chensue, SW 1993. The role of macrophage inflammatory protein-1 alpha in Schistosoma mansoni egg-induced granulomatous inflammation. $J$ Exp Med 177: 1551-1559.

Lukacs NW, Strieter RM, Shaklee CL, Chensue SW, Kunkel SL 1994b. Macrophage inflammatory protein-1 $\alpha$-/- influences eosinophil recruitment in antigen-specific airway inflammation. Eur J Immunol, 25: 245-251.

Machado FS, Koyama NS, Carregaro V, Ferreira BR, Milanezi CM, Teixeira MM, Rossi MA, Silva JS 2005. CCR5 plays a critical role in the development of myocarditis and host protection in mice infected with Trypanosoma cruzi. J Infect Dis 191: 627-636.

Mackay CR 2001. Chemokines: immunology's high impact factors. Nat Immunol 2: 95-101.

Maurer M, Von Stebut E 2004. Macrophage inflammatory protein-1. Int J Biochem Cell Biol 36: 1882-1886.

Menten P, Wuyts A, Van Dame J 2002. Macrophage inflammatory protein-1. Cytokine Growth Factor Rev 13: 455-481.

Murphy PM, Baggiolini M, Charo IF, Hebert CA, Horuk R, Matsushima K, Miller LH, Oppeinheim JJ, Power CA 2000. International Union of Pharmacology. XXII. Nomenclature for chemokine receptors. Pharmacol Rev 52: 145-176.

Nibbs RJ, Wylie SM, Pragnell IB, Graham GJ 1997. Cloning and characterization of a novel murine beta chemokine receptor, D6. Comparison to three other related macrophage inflammatory protein-1alpha receptors, CCR-1, CCR-3, and CCR-5. J Biol Chem 272: 12495-12504.

Nobre V, Silva LC, Ribas JG, Rayes A, Serufo JC, Lana-Peixoto MA, Marinho RF, Lambertucci JR 2001. Schistosomal myeloradiculopathy due to Schistosoma mansoni: report on 23 cases. Mem Inst Oswaldo Cruz 96: 137-141.

Oliveira DM, Silva-Teixeira DN, Goes AM 1999. Evidence for nitric oxide action on in vitro granuloma formation through pivotal changes in MIP-1 $\alpha$ and IL-10 release in human schistosomiasis. Nitric Oxide 6: 162-171.
Olson TS, Ley K 2002. Chemokines and chemokine receptors in leukocyte trafficking. Am J Physiol Regul Integr Comp Physiol 283: R7-28.

Post TW, Bozic CR, Rothenberg ME, Luster AD, Gerard N, Gerard C 1995. Molecular characterization of two murine eosinophil beta chemokine receptors. J Immunol 155: 52995305.

Proudfoot AE 2002. Chemokine receptors: multifaceted therapeutic targets. Nat Rev Immunol 2: 106-115.

Proudfoot AE, Power CA, Rommel C, Wells TN 2003. Strategies for chemokine antagonists as therapeutics. Sem Immunol 15: 57-65.

Proudfoot AE, Power CA, Wells TN 2000. The strategy of blocking the chemokine system to combat disease. Immunol Rev 177: 246-256.

Qiu B, Frait KA, Reich F, Komuniecki E, Chensue SW 2001. Chemokine expression dynamics in mycobacterial (type 1) and schistosomal (type 2) antigen-elicited granulomatous inflammation. Am J Pathol 158: 1503-1515.

Ritz SA, Cundall MJ, Gajewska BU, Swirski FK, Wiley RE, Alvarez D, Coyle AJ, Stampfli MR, Jordana M 2004. The lung cytokine microenvironment influences molecular events in the lymph nodes during Th1 and Th2 respiratory mucosal sensitization to antigen in vivo. Clin Exp Immunol 138: 213-220.

Rutitzky LI, Hernandez HJ, Stadecker MJ 2001. Th1-polarizing immunization with egg antigens correlates with severe exacerbation of immunopathology and death in schistosome infection. Proc Natl Acad Sci USA 98: 13243-13248.

Rutitzky LI, Lopes RJR, Stadecker MJ 2005. Severe CD4 T Cell-Mediated immunopathology in murine schistosomiasis is dependent on IL-12p40 and correlates with high levels of IL-17. J Immunol 175: 3920-3926.

Schrum S, Probst P, Fleischer B, Zipfel PF 1996. Synthesis of the CC-chemokines MIP-1 $\alpha$, MIP-1 $\beta$, and RANTES is associated with a type 1 immune response. J Immunol 157: 3598-3604.

Silva LC, Maciel PE, Ribas JG, Souza-Pereira SR, Serufo JC, Andrade LM, Antunes CM, Lambertucci JR 2004. Schistosomal myeloradiculopathy. Rev Soc Bras Med Trop 37: 261272.

Siveke JT, Hamann AT 1998. T helper 1 and T helper 2 cells respond differentially to chemokines. J Immunol 160: 550554.

Sousa-Pereira S, Teixeira AL, Silva LC, Souza AL, Antunes CM, Teixeira MM, Lambertucci JR 2006. Serum and cerebral spinal fluid levels of chemokines and Th2 cytokines in Schistosoma mansoni myeloradiculopathy. Parasite Immunol (in press).

Souza AL 2005. Papel de MIP-1 $\alpha / C C L 3$ e do receptor CCR 5 na infecção por Schistosoma mansoni, Thesis, Universidade Federal de Minas Gerais, Belo Horizonte, 144 pp.

Souza AL, Roffê E, Pinho V, Souza DG, Silva AF, Russo RC, Guabiraba R, Pereira CA, Carvalho FM, Barsante MM, Corrêa-Oliveira R, Fraga LA, Negrão-Corrêa D, Teixeira MM 2005. Potential role of the chemokine macrophage inflammatory protein 1alpha in human and experimental schistosomiasis. Infect Immun 73: 2515-2523. 
Stadecker MJ, Asahi H, Finger E, Hernandez HJ, Rutitzky LI, Sun J 2004. The immunobiology of Th1 polarization in high-pathology schistosomiasis. Immunol Rev 201: 168179.

Vennervald BJ, Dunne DW 2004. Morbidity in schistosomiasis: an update. Curr Opin Infect Dis 17: 439-447.

Vierboom MP, Zavodny PJ, Chou CC, Tagat JR, Pugliese-Sivo C, Stritzki J, Steensma RW, McCombie SW, Celebi-Paul L, Remarque E, Jonker M, Narula SK, Hart B 2005. Inhibition of the development of collagen-induced arthritis in rhesus monkeys by a small molecular weight antagonist of CCR5. Arthritis Rheum 52: 627-636.

Warmington KS, Boring L, Ruth JH, Sonstein J, Hogaboam
CM, Curtis JL, Kunkel SL, Charo IR, Chensue SW 1999. Effect of C-C chemokine receptor 2 (CCR2) knockout on type-2 (schistosomal antigen elicited) pulmonary granuloma formation: analysis of cellular recruitment and cytokine responses. Am J Pathol 154: 1407-1416.

Welniak LA, Wang Z, Sun K, Kuziel W, Anver MR, Blazar BR, Murphy WJ 2004. An absence of CCR5 on donor cells results in acceleration of acute graft-vs-host disease. Exp Hematol 32: 318-324.

Zhou Y, Kurihara T, Ryseck RP, Yang Y, Ryan C, Loy J, Warr $\mathrm{G}$, Bravo R 1998. Impaired macrophage function and enhanced $\mathrm{T}$ cell-dependent immune response in mice lacking CCR5, the mouse homologue of the major HIV-1 coreceptor. J Immunol 160: 4018-4025. 